\title{
System-level Causal Modelling of Widescale Resource Plundering: Acting on the Rhino Poaching Catastrophe
}

\author{
Hildegarde Koen*a,b, Henk Roodt ${ }^{\mathrm{c}}$, JP de Villiers ${ }^{\mathrm{a}, \mathrm{b}}$ \\ ${ }^{a}$ Defence Peace Safety and Security (DPSS), Council for Scientific and Industrial Research \\ (CSIR), PO Box 395, Pretoria 0001, South Africa, \\ hkoen@csir.co.za,jdvilliers1@csir.co.za \\ ${ }^{b}$ Department of Electrical, Electronic and Computer Engineering University of Pretoria, \\ Private Bag X20, Hatfield, 0028, Pretoria, South Africa \\ ${ }^{c}$ Centre For Transdisciplinary Research and Innovation, Waikato Institute of Technology, \\ Hamilton, New Zealand, \\ henk.roodt@wintec.ac.nz
}

\begin{abstract}
The initial goal of this study was to develop a predictive model that could serve as a pre-emptive method for curbing rhino poaching. During the development of the predictive model it became evident that only the tip of the iceberg, so to speak, has been uncovered. The rhino poaching problem is even more complex than was initially thought and this paper serves as a reflective piece on how the research methodology for the complex and poorly understood rhino poaching problem was shifted towards developing a common understanding of major drivers and interactions, to allow for pre-emptive action on a variety of fronts. The global drivers dictating the rhino horn supply chain such as human trafficking and other socio-economic factors cannot easily be captured in a model of causal certainties. This is in spite of the fact that the motivation of the individual poachers may reduce to greed or the need to provide for their families. Although the authors initially thought that it would be possible to model these causalities it became clear that the system is highly reflexive and adaptive. The system has feedback and recursive causal internals that self-regulate by changing in response to the environment. As interventions are introduced, the system will try to respond to mitigate the effects or impact of the change which
\end{abstract}

${ }^{*}$ Corresponding author 
makes predictive causal modelling very challenging. The paper reflects on this understanding derived from the development of a methodology that combines different versions of a causal Bayesian Network model with a systems framework drawn from an integral ecology perspective.

Keywords: transdisciplinary approach, rhino poaching, systems engineering

\section{Introduction: The State of Rhino Poaching in South Africa}

Rhino poaching has reached catastrophic levels over the past few years. Sadly, what was once headline news has now become just another story in the newspaper. During 2015 the rhino poaching problem seems to have stabilised somewhat with a slight decrease in the number of poaching attacks from previous years (Modise, 2016). The reality is that rhino poaching is still a big problem, with no signs of ending before the last rhino in the wild has been taken by poachers.

In 2008 the poaching numbers started to increase drastically ( 83 rhinos were poached), and kept on increasing at an alarming rate until a total of 1175 rhinos were poached during 2015 (Modise, 2016). That is more than three rhinos every day. The biggest problem is experienced in the Kruger National Park (KNP) which is home to the largest concentration of rhinos in South Africa (Emslie \& Brooks, 1999). The KNP lies on the border between South Africa, Zimbabwe and Mozambique, which makes it easier for poachers to escape, and the geographical diversity and different political systems increase the overall complexity of the problem.

While the motivation of the individual poachers may be simplified to being driven by a need for income, as already mentioned, the global drivers dictating the various contributing factors cannot easily be captured in a simple causal model. Many different approaches have been followed to combat the rhino poaching problem, but without real long-term success. These methods range

from deploying the military in the KNP (Mouton, 2012), to injecting rhino horns with poison (Gosling, 2012), to erecting extra fences and employing sniffer dogs 
(Gosling, 2012).

Our belief is that neither technology nor manpower alone is the key to resolving this problem, but that a sound shared understanding supported by mathematical models will shift the balance of power to the law and protection enforcement agencies. The rhino poaching problem should thus be viewed from the perspective of a system of systems (Ackoff, 1971), (Forrester, 1994), (Jackson \& Keys, 1984), (Boardman \& Sauser, 2006) using carefully selected mathematical as well as qualitative approaches. Muntifering et al. (2015) agree with our statement that rhino poaching is a complex problem "...that is interconnected with other problems across multiple scales, making solutions elusive."

No system of inquiry of this nature is ever free of value judgements and the choices made to truncate certain aspects of the system (boundary setting) to make the study tractable will be detailed. The authors acknowledge that the system under study is reflexive (the complex problem is framed with relevance to and in the participating society that is required to change) (Finlay, 2008) and in the next section the "wicked" (Rittel \& Webber, 1973) nature of the problem is considered in more detail. This will be followed by a brief discussion of the methods considered for modelling of the domain that could capture, refine and share the knowledge of the problem.

\section{The Intractable Nature of the Rhino Poaching Problem}

As far back as 1973 a Professor of the Science of Design and his colleague in City Planning at the University of California, Berkeley, recognised that in certain challenges we face in the world there is inadequate information to develop robust theory to develop reliable forecasting and prediction systems (Rittel \& Webber, 1973). Rittel and Webber recognised that problems that have a significant societal context are very different from the problems that yield to reductionism. They called this class of problem "wicked". Policy issues, ethics, morality, human nature, and collective reflexive behaviour stand in the way of a proper formulation of the problem. It is exceedingly difficult to develop a 
set of possible solutions without a structured problem statement. It is human nature to consider the obvious outcome (in this case, rhinos being slaughtered) and to assume that if the rhinos are adequately protected (say by law and funding resulting from political rallying), the poaching will stop. The definition of adequate protection implies a collection of important considerations.

Unforeseen consequences may arise while addressing a wicked problem, going hand-in-hand with the fact that wicked problems can have many causes, often hidden and driven by subtle motivations. The resolution of wicked problems, rather than the "ultimate" solution to wicked problems, requires a change of behaviours, as they are often caused by a set of failing policies (Australian Public Service Commission, 2007).

It became clear early on in the study that rhino poaching, like other forms of resource plundering, is driven by a multitude of linked societal, financial and political factors. Considering the work of others in changing criminal behaviour (Craglia et al., 2000), (Mohler et al., 2011), (Wang et al., 2013), (Short et al., 2014) and the influence of gangs, it became evident that the rhinos are a commodity of trade. As it was put simply during a work session, the rhinos cannot be influenced to do anything to protect themselves: they just do what rhinos do - graze and live a rhino life. This simple behaviour makes the rhino and other species vulnerable within a context of a global trade that includes rhino horn, elephant tusks and humans as part of the mix of commodities. The implication is that adequately dealing with the problem of resource plundering will not only benefit rhinos, but will shift the scope of the understanding to include any other vulnerable entity.

\section{Motivation behind the Design of the Study}

Brown et al. (2010) state that the inquiry into a wicked problem is usually triggered by a crisis event. The initial response can come from any actor involved in the situation and may be extended to include other affected parties. The initial response may take the form of a policy intervention, the use of technology 
focussed on the perceived problem (where rhinos are the targets, compared to the real problem where the rhinos are the commodities), or it can be academic in nature or as a result of societal action, amongst others. In the case of the rhino poaching problem, a range of responses was triggered.

Clearly the design of a study to capture the knowledge gained during these attempts at solving the problem must allow for the capture and validation of individual expert knowledge, organisational learning, and societal understanding. In order for the study to be approached holistically, these contextual world views surrounding the problem (and the hidden problem areas) need to be made explicit (using structured and mathematically sound what-if analysis for example), captured, and validated in a common "model of understanding" that is open to inspection and debate amongst "open, inclusive minds". Open and inclusive minds will be more willing to accept conceptual models created in this nontraditional and collaborative way. The Australian Public Service Commission (2007) also state that "innovative and flexible approaches" built on experimentation and evaluation are needed. It is within this context that qualitative and quantitative models can play an important role in supporting experimentation and insight development. Models force assumptions to be made explicit and as Peter Allen states, any representation of reality without assumption is 'subjective reality' that does not contribute to new knowledge and understanding Allen, 2000).

Although it is understood that wicked problems can only be untangled to a degree and that a complete solution may never be found (Rittel \& Webber, 1973), the aim is to shift the behaviour of the different players involved in the problem towards a turning point that resolves the problem to a degree in the long term. We envision the rhino poaching problem to be such an ongoing problem, and believe that by changing the behaviour of the various players, a turning point may be reached before the rhino population drops below critical numbers for species survival. The turning point may be seen as a possible "stopping flag" for the process, a guard that will flag regression towards the previous state.

Often processes that drive wicked problems are inherently recursive accord- 
ing to Morin (2008). Morin explains that a cause can produce an effect that is required for their own causation - the process calls on itself to generate itself. As is the case with rhino poaching, the more we understand the system, the more it understands itself and changes in response to the new understanding. Any introduced change to shift the system becomes part of the system! This is a result of the intricate nature of the societal aspects that contribute to the continued poaching, which includes unintended leaking of aspects of ideas and plans.

The research must thus try to unearth the driving dynamic patterns behind it if it wants to bring a radical shift in the outcome of events in the system, breaking the recursive causality. Patterns imply a certain amount of predictability (patterns are inherently repeatable), but we concede that past experience is of limited value when predicting the future state of the system in this case. The system may deviate rapidly once the pattern is disturbed in the slightest. However, when our approach is to rather consider the diversity of the driving forces and the possibility of outcomes given certain interventions, the broader behavioural trends of the system can become known to a wider knowledge base. The tipping point required to shift the understanding of the problem domain can then be devised using the wider model (Roodt, 2015).

Considering the above, it is clear that working collaboratively across boundaries and engaging stakeholders are required to capture the initial collective understanding. The information may be synthesised into a "model" of common understanding, and validated against the collective knowledge base, allowing for new and innovative approaches to be generated and captured in a more robust process, which will in turn improve the model. The model may be analysed and tested in the field, taking into account that the system contains social agents that will have a complex response to any intervention. This experimental approach to new learning may be used to update the model of patterns until progress is made towards approaches that may, in all likelihood, shift the problem domain towards a desired tipping point.

Hadorn et al. (2007) describes the process that is inclusive and collaborative 


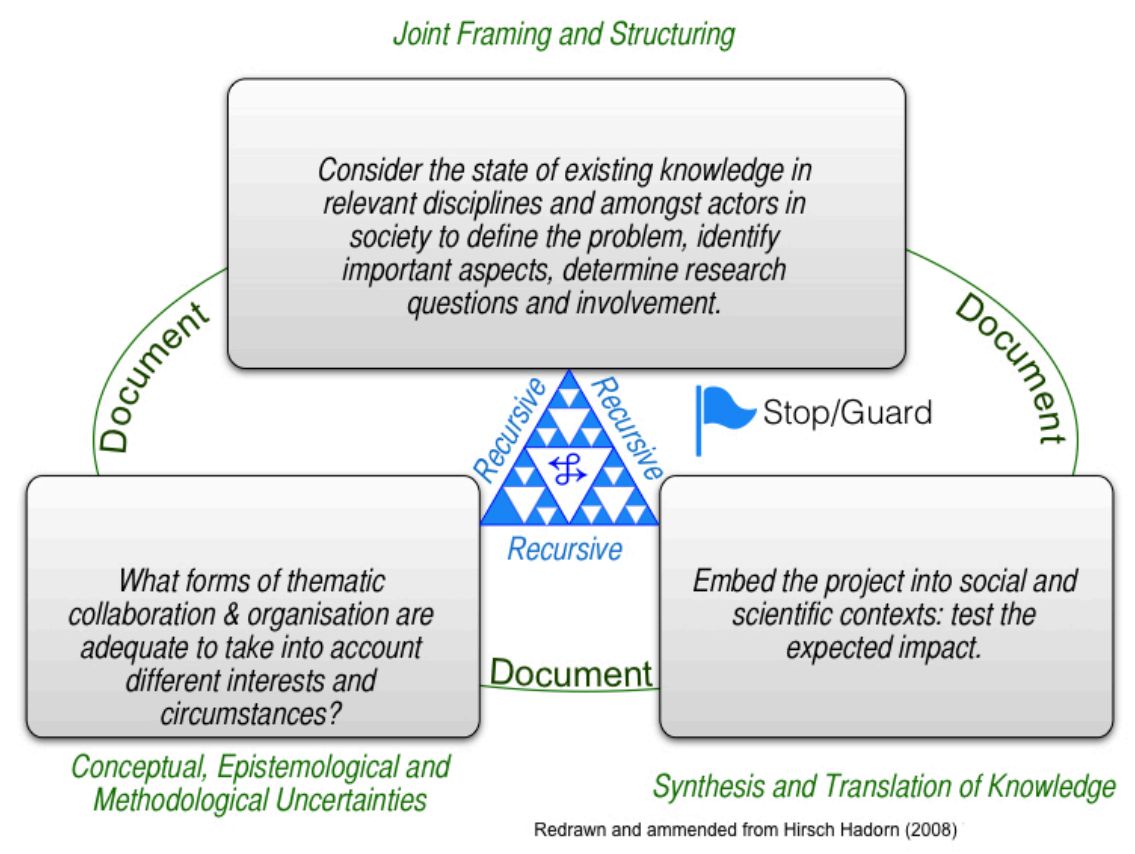

Figure 1: A recursive process that accounts for diversity of disciplines to contribute to problem resolution.

and points out that understanding of the wicked problem can be increased without extensive simplification. This approach is not similar to the typical "V" process of systems solution engineering as described by Forsberg \& Mooz (1991). Although the iterative nature required of the study can be resolved with "nested V" procedures, the recursive and evolutionary nature of the problem requires a commensurate research methodology, which is shown in Figure 1 .

Developing new (core) skills and competencies are important responses to wicked problems. For this study, communication with various stakeholders, documentation of the entire process, and big picture thinking towards addressing the rhino poaching problem were developed and nurtured. Collaboration had to be established between different agencies, such as researchers, rangers, and safeguarding entities, and between different fields such as engineering and ecology. 
The next section will discuss in detail how a causal model, specifically a Bayesian Network model, was developed as an initial perspective model. This model was used as the starting point for an expert workshop. The purpose of the expert workshop was to evaluate the model and offer insights into how realistic and feasible it is. This led to multiple iterations of the BN model up until an iteration deemed realistic by experts was found.

\section{The Design and Implementation of the System Models}

Based on the earlier discussion, a systems modelling approach was considered. The design of the study and the models go hand-in-hand and are described in this section. The understanding gained and the problems encountered are discussed and in the subsequent section the final contextual shift, that lead to our final results, will be covered.

\subsection{Systems Modelling}

The original thesis was that a predictive model could be developed to reduce the surface area that needed patrolling by rangers in order to prevent poaching events from occurring. An alternative policing approach would also have to accompany this predictive model, such as predictive policing whereby the policing units (in this case, the rangers), adapt their way of policing by using mathematics and predictions such as mentioned by Inayatullah (2013).

Earlier in the paper the linked, and possibly non-linear, nature of the problem was discussed. The system may have feedback and circular, or even recursive, loops that cause the system to self-regulate and adapt to events in the environment. With consideration of our arguments before, two broad philosophical approaches present themselves. Firstly, we can follow the Santa Fe approach and try to study the multiple intertwined processes and actors that comprise the system in an effort to retrospectively uncover the patterns or laws that predominantly shape the system (Morin, 2007). The hope is that we can discover the simple rules or patterns that will give rise to complex emergent 
phenomena. Or we can subscribe to the position that a complex system cannot be cut up in any way that will reveal the underlying simple drivers, because what is fundamentally of interest is the unfolding dynamics and local interrelationships in the system. If we agree that complex systems are irreducible in the normal sense of reductive science, we are forced to commit to a self-critical rationality (according to Woermann \& Cilliers (2012)), which acknowledges the subjective nature of the research effort. This subjective approach is not a license for anything goes, but requires careful consideration and assumption about the system under scrutiny. With this in mind, at least two mathematical approaches to modelling the causal nature of the problem presented itself: System Dynamics (SD) and Bayesian Networks (BN) both allow for the capture of knowledge about the causalities in the system.

It is appropriate to use SD as the method to capture and understand the system better when the focus of a study is on the non-linear behavioural aspects of a system as it evolves over time. SD uses a continuous model of the world, where a collection of coupled first order differential equations can be used to describe the causal behaviour of the system. Schaffernicht (2007) reflects on work by Halpern \& Pearl (2001) and points out that SD would be an appropriate modelling method if we were interested in the broad behaviour of the system over time.

However, our interest is in discovering the pattern of events that may be necessary precursors to poaching events. In this sense we are interested in the likelihood of a rhino being poached in a specific geographical area, given that a set of other events occur, each with associated likelihoods. Halpern and Pearl consider the use of empirical data which in our case include, but are not be limited to, the historical recordings of poaching events. BNs capture causality as directed arcs between events that have likelihoods associated with them.

Obtaining good-quality data for a multi-faceted problem as intricate as this is a challenging task, but a lack of hard published data can often be overcome by using expert knowledge wisely. BNs are very flexible in that they can handle expert knowledge as well as empirical data on an equal footing. This requires 
high levels of collaboration as experts from many different perspectives and technical backgrounds are needed to populate the model, adding to the mix the old problem of bringing together experts from different disciplines in the same room to contribute to a balanced new understanding of the bigger picture. As discussed, it also requires a research methodology that can cope with the recursive and entangled nature of the topic under scrutiny. In Popa et al. (2015) the authors state that a transdisciplinary approach does not intend to necessarily construct a "common theoretical framework", but rather promote self-reflection. Combining this approach with a methodology to capture the insights and to make it available as artefacts (models for inference and decision making in this case) that could readily be used by a diverse interest group for reasoning about the problem, was seen as a valuable contribution.

Given the arguments above, it was decided to use a BN as the model structure, as BNs can adapt and effectively handle missing and incomplete data. BNs can also be populated with "expert knowledge" in the event of insufficient recorded data and capturing the narratives of people immersed in the reality of the system. We use the term "expert knowledge" here to describe the knowledge and understanding of people with experience in any area we discover that may be of utility in adequately dealing with the complexity of the problem, including cultural and societal narratives. Furthermore, using a BN to capture an agreed upon set of initial drivers and to indicate when and where the next poaching attacks are likely to occur, can be used to co-create and enhance the shared understanding, which is a pre-requisite for good decision making (Roodt \& Koen, 2014).

Finally BNs can be used in different modes of reasoning, depending on the situation; the main goal of the BN in this study is to provide probabilities of poaching events occurring in certain areas. Furthermore, knowing the details of poaching events can aid in discovering patterns that translate to the scenarios in which poaching events can occur. 


\subsection{The Initial Perspectives Model}

The initial outline of the project was rather simplistic: find out which variables and scenarios lead to poaching events and use them to predict where successive poaching events are likely to occur. The authors, in collaboration with colleagues at Thales, Delft (Netherlands), developed a BN that was previously referred to as a "current perspective" model in the paper by Koen et al. (2014). This model is called the "initial perspective" model in this paper in order to avoid confusion. This initial perspective model is shown in Figure 2 ; it contains all the elements and causal links that the authors considered relevant to the problem.

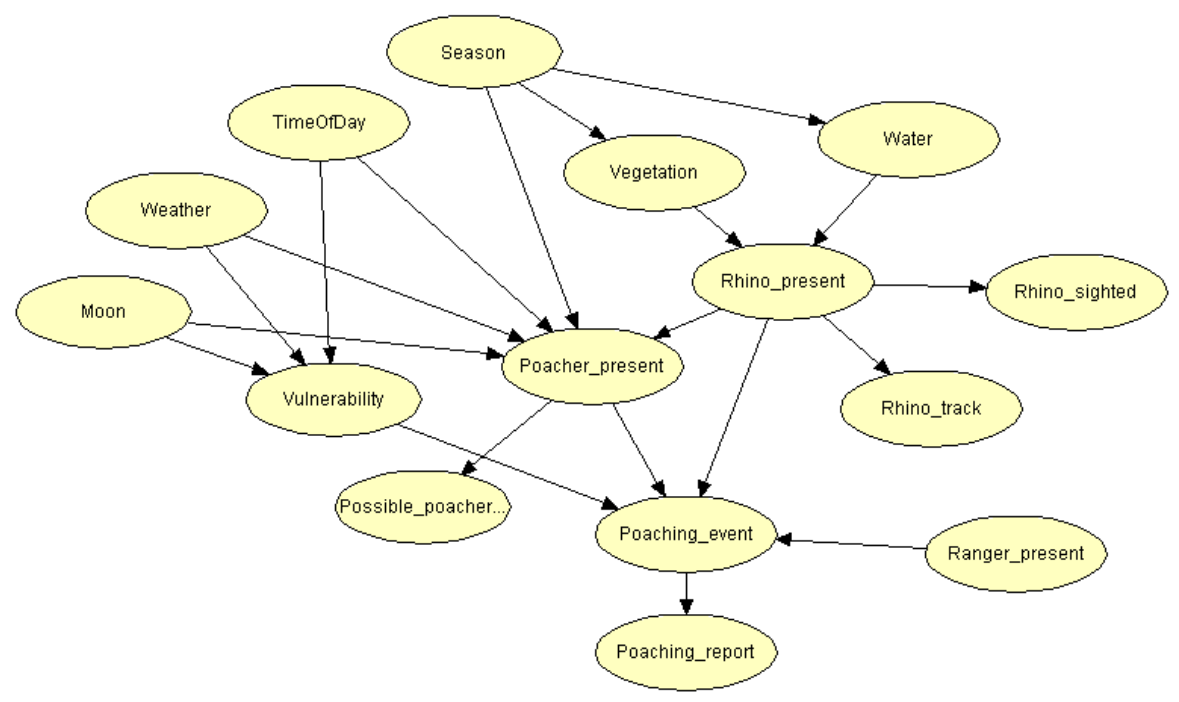

Figure 2: Initial perspective expert knowledge Bayesian Network

The reason a first-draft model was developed, in contrast to the traditional clean slate approach, was to cater for time and availability constraints of the experts, and to capture an initial synthesis of the understanding of the problem space. Owing to the serious and sensitive nature of the problem, it was extremely difficult to get all the relevant experts together for a three-day workshop. The workshop was also held roughly 450 kilometres from where most of 
the experts are situated; hence it was expensive and time-consuming to have all the relevant experts at the workshop. However, we succeeded in holding a three-day workshop with a sufficient number of relevant experts.

\subsection{Expert Workshop}

The model shown in Figure 2 was used as a template to elicit discussions from the experts in the workshop. One objective of the workshop was to gauge the experts' reaction towards the model as this was the first model of its kind with respect to rhino poaching. This was also done to cultivate ownership of and obtain "buy-in" from the experts. These experts could have influence on policies, and therefore it was clear that it was better for the outcome of the project to get the experts involved from the start.

The other objective of the workshop was to have the experts evaluate, qualify, and verify the computerised BN model (Sargent, 2005). They were asked to study and trace the logic of the model and suggest redundancies and possible augmentations to enhance the conceptual model fidelity (Knepell \& Arangno, 1994). The comments confirmed the premises of the authors when the model was developed and the experts agreed that the model was a good representation of their understanding. The model was updated with inputs that reflected the intended use, the historical analysis by the experts, and their insights into the current situation.

\subsection{The New Rhino Poaching Model}

The outcome of the expert workshop was a conceptual model that was better suited to the real-world. Several key experts could not attend the workshop, thus a few one-on-one interviews were set up between the main author and these experts. The model that resulted from the workshop as well as the subsequent interviews is shown in Figure 3

When comparing the two models, it is interesting to note that in Figure 3 there are easily distinguishable subgroups: one for poachers, one for rhinos, and one for rangers. All of these subgroups feed into the main (core) variable: 
whether or not a poaching event is going to occur. This was an interesting result that came to be after the expert workshop. The different subgroups could then be shown to the relevant experts in interviews, without overloading them with the entire network at once. The rhino subgroup, for instance, was shown to rhino ecologists, and the poacher subgroup to criminal investigators.

The experts were allowed to consider aspects of the problem that they could equate to patterns that they were familiar with. The authors were well aware of the fact that their presence and interventions could influence the outcomes, but Finlay (2008) points out that the key to the reflexivity (in this case, the deliberate immersion of the researchers and other actors that are also part of the problem space: wardens in the park, for example) that is introduced by the researchers, is to be sensitive to how this is done. In this case the approach was to favour focus on experience over broad discussion that could lead to "favourable" positioning of disciplines.

\subsection{Problems Encountered}

During the refinement of the network, several problems were encountered. Different strategies were tested by the guardians of the KNP to curb the rhino poaching problem, and it became evident that the phase of the moon is an important driver for poaching attacks. Each full moon thereafter, a group of rangers were sent to poaching hot spots to intercept the poachers. The poachers had to change their strategy in order to avoid capture, thus the full moon became less of an important driver for poaching attacks. This is but one example of where the system adapted to the introduced actions to curb poaching. The system is reflective (it has the ability to investigate itself in essence to understand

changes) and adaptive and learns when factors are altered, as expected. The problem with this is that the rhinos do not learn or adapt, only the people in the system who see them as a commodity, learn and adapt!

The individuals who poach the rhinos are a layer removed from the researchers investigating the rhino poaching problem. These individuals abuse the society around the KNP to do their bidding and the perpetrators have 
agents who harvest the commodity. The researchers of this problem do not see the real perpetrators, they only see the effect on the commodity, thus the system has an intelligent layer that learns and reflects apart from the rest of the system. 


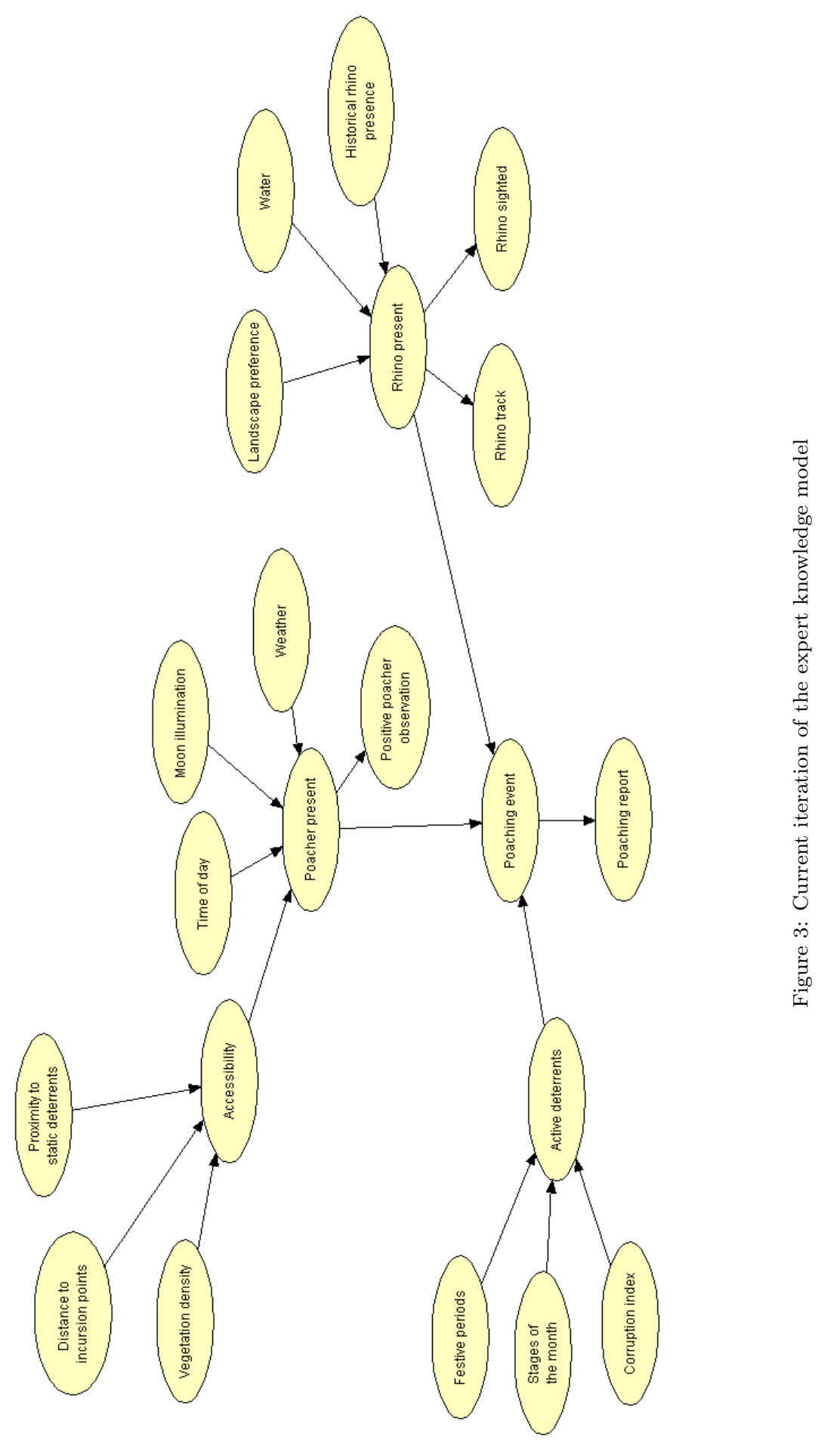


This reflective and reflexive/adaptive nature of the system complicates matters significantly with respect to training and testing the model. The data only indirectly show where or when the policy changes occurred, or when the behaviour of the rangers or the poachers changed. Training the model on this data would not yield correct results, as the important drivers (variables) are not known. The analysis of the data facilitated the identification of whether drivers were very important or not. If the model could be retrained at regular enough intervals with enough data, it may be able to capture changes in behaviour, albeit indirectly.

The model in its current form also cannot be trained or tested only with the available data because there exist several abstract variables in the model for which the data do not exist (think of Accessibility, for instance). There is also no data for non-poaching events (poaching gone wrong or aborted, or poaching attacks that never happened in the first place), only for poaching events.

In order for the model to provide valid predictions, the model needs to be trained on a dataset which is based on a stable set of rules or patterns. However, the patterns have been shown to be temporally varying and adaptive. Training this model requires a method to capture the temporal nature, such as periodic re-training. That temporal changing nature is a result of our actions and is unpredictable with regards to how the system adapts to what we do.

\section{Shifting the Rhino Poaching Problem to a Broader Context}

It is evident that the problem is not just about rhinos and poachers. There are various elements at work (social, economic, religious, etcetera), and each of these elements can be discussed in detail. Together, the elements form a comprehensive picture of the problem, but for the scope of this work, only the elements directly influencing the confines of the KNP are considered. This is an initial, and necessary truncation (boundary setting) of the system in order to develop a mental model that can be grasped by a broad group of stakeholders. Political views were excluded as these were seen as aspects that would be the 
target of decision making, rather than drivers for decisions; we are working to influence political directives. This is an important decision that splits a layer of feedback in the system in an attempt to shift the focus to those elements that are directly influenced by decisions made by those in daily interaction with the practicalities of the problem. This was also a requirement set by the funding agencies for the broader set of projects. The result is that the outcome of the study may be used to address the political decision makers, which in turn means that the models and communication instruments must be designed to communicate effectively.

\subsection{A New Mental Model of the Problem}

In the book by Esbjörn-Hargens \& Zimmerman (2009), the case is made for integral ecology which draws together different paradigms and answers the call for greater collaboration across a wide range of areas. According to EsbjörnHargens \& Zimmerman (2009), the problem framework can be divided into four quadrants; these are shown in Figure 4 which was redrawn from their paper.

The vertical axes are divided into Individual and Collective and illustrate the distinction between the thought processes of individuals and groups. In the middle of the figure where the quadrants meet, the current reality is reflected. In this case, the current reality is more than a thousand poached rhinos per year in South Africa. The factors listed in each quadrant depict the methodology used by each group of experts in that quadrant to solve the problem.

The upper left quadrant (UL) reflects the psychological and phenomenological inquiry of the problem. The psychological and phenomenological inquiry is an integral approach that includes the exploring of beliefs, emotions, and selfidentities. Table 1 illustrate possible questions that could be answered in this quadrant include.

The upper right quadrant (UR) is concerned with the behavioural and physiological analysis of the problem. Behavioural and physiological analysis include empirical, chemical, and biological elements. Questions in this quadrant include: What are the problem behaviours that we want to change? What are 




Figure 4: The four quadrants of the mental model (redrawn from Esbjörn-Hargens \& Zimmerman (2009))

the behaviours that we want to encourage?

The lower right quadrant (LR) is concerned with the ecological and social assessments, whereas the lower left quadrant (LL) is concerned with the cultural and world view investigations of the problem. Ecological and social assessments include environmental, political, educational, legal, and economic elements. These assessments can be done with a STEEP (Social, Technological, Economic, Environmental, Political) analysis which is used mainly in marketing to compare different external factors that can impact an organisation. Cultural and worldview investigations include philosophical, ethical, and religious ele- 
Table 1: UL quadrant questions and answers

\begin{tabular}{|c|c|}
\hline Question & Possible answer \\
\hline $\begin{array}{l}\text { 1. What do people think and feel about the } \\
\text { rhino poaching problem? }\end{array}$ & $\begin{array}{l}\text { Think that it is solvable } \\
\text { Feel that it is unnecessary } \\
\text { and based on myths }\end{array}$ \\
\hline 2. What emotions does it evoke? & $\begin{array}{l}\text { Anger, helplessness, sadness } \\
\text { frustration }\end{array}$ \\
\hline 3. What values are involved? & $\begin{array}{l}\text { greed, sustainable tourism, } \\
\text { environmental protection }\end{array}$ \\
\hline 4. Why do poachers poach? & desperation, financial gain \\
\hline 5. What is their psychological profile? & $\begin{array}{l}\text { desperate, poor, struggling, } \\
\text { greedy, opportunistic }\end{array}$ \\
\hline $\begin{array}{l}\text { 6. What happens during a poaching attack } \\
\text { with regards to emotions? }\end{array}$ & $\begin{array}{l}\text { poachers are calculated, } \\
\text { and superstitious }\end{array}$ \\
\hline $\begin{array}{l}\text { 7. What are the poachers' belief regarding } \\
\text { poaching? }\end{array}$ & $\begin{array}{l}\text { rhinos are just animals, } \\
\text { there for the taking }\end{array}$ \\
\hline
\end{tabular}

ments. Questions that are answered in this quadrant include: What world views and discourses are relevant? What symbols, myths, metaphors, and stories are relevant?

Studying each quadrant, it can be decided which area of the problem is covered, and also by whom (which type of expert is responsible for which part in which quadrant?). This was especially helpful in planning the workshop.

Not all of the quadrants are represented in the workshop as it falls outside the scope of the model. UR and LR were represented by experts in the workshop, but all four quadrants work together to place the work in context within the literature. 


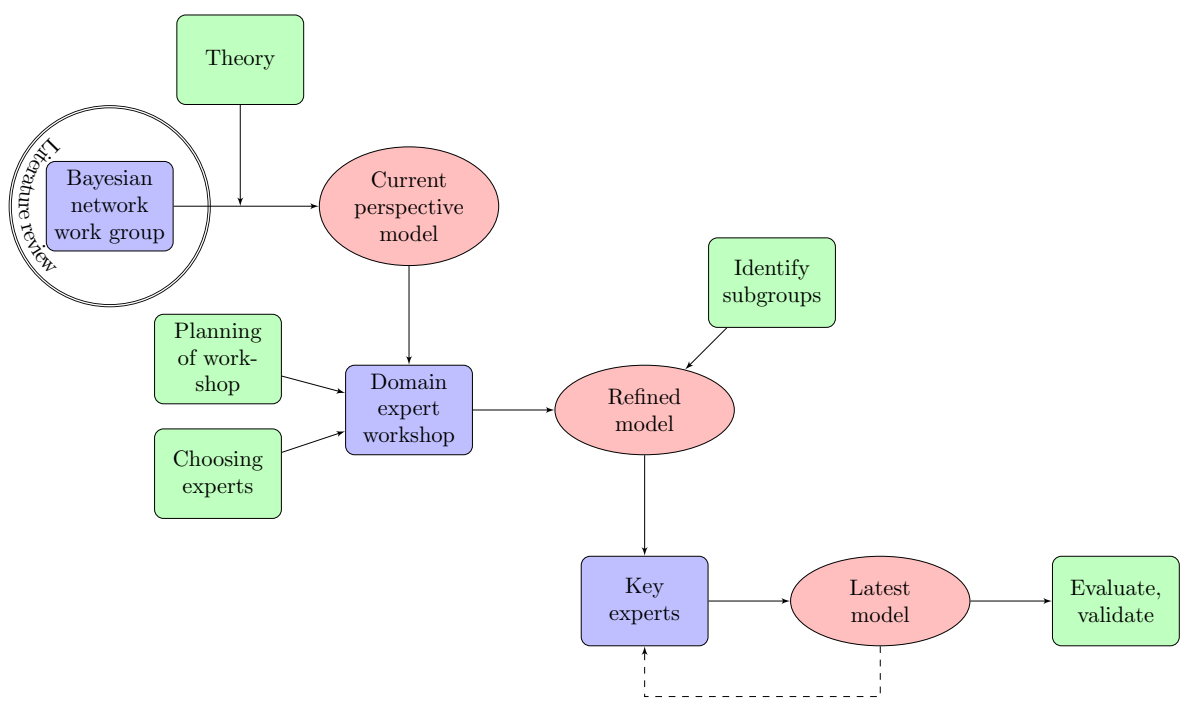

Figure 5: Developing a co-created understanding and model

\subsection{Progression of Understanding}

Figure 5 depicts the structured development of the understanding of the problem. The blue blocks signify times when experts were involved, the pink ovals signify new model iterations, and the green blocks signify extra work that had to be done. The "latest model" presents the stakeholders with a map of likelihoods of poaching superimposed on a geographical map of the whole of the KNP, a so-called probability "heat map". This graphical representation was discussed and verified for consistency as part of a confidence assessment by experts in the different sub-fields involved; it is briefly presented in the next section.

\section{Bringing Results to Fruition}

The output of the final set of expert consultations, in terms of the knowledge that was gained, can be illustrated by a heat map as was mentioned in the previous section. This map is the culmination of the research effort in terms of moving closer to the resolution of the rhino poaching problem. Using the BN 
model, posterior probabilities for poaching events were calculated and plotted; the lighter the colour, the higher the probability of a poaching event occurring in a geographical cell. The question now is not whether or not the model can predict; the question is whether the patterns can support the decision makers to implement preemptive actions with confidence. The model can be used as a pattern what-if tool to evaluate possible outcomes of actions. This fits better with the required agile adaptive approach (such as the spiral approach described in Korb \& Nicholson (2010) ) to the constantly changing problem: "Rather than working towards a consolidated baseline of a requirement/solution, the requirements are diverse and evolving as the understanding of the problem domain improves." (Roodt \& Koen, 2014)

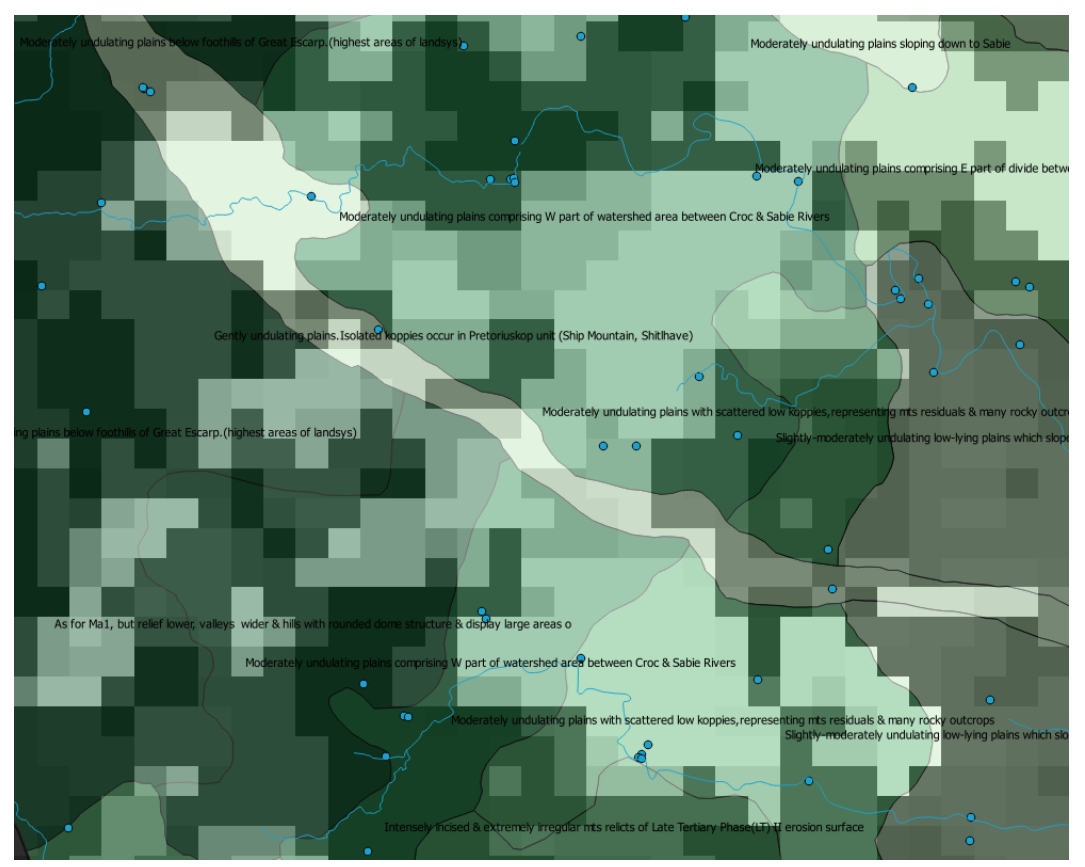

Figure 6: Geology map and predicted heat map overlaid

Figure 6 illustrates a small zoomed in area of the predicted poaching event heat map for the KNP overlaid with the geology map. The lighter the heat map, the higher the probability of a poaching event. Owing to the sensitivity of the 
problem, only a small portion of the maps can be shown. Figure 7 and Figure 8 show the geology map and the landscape preference prior map respectively. Figure 9 illustrates the geology map and the landscape preference map overlaid. The lighter areas are preferred by the rhinos, and the darker areas are less preferred, and we can see that the two maps correspond.

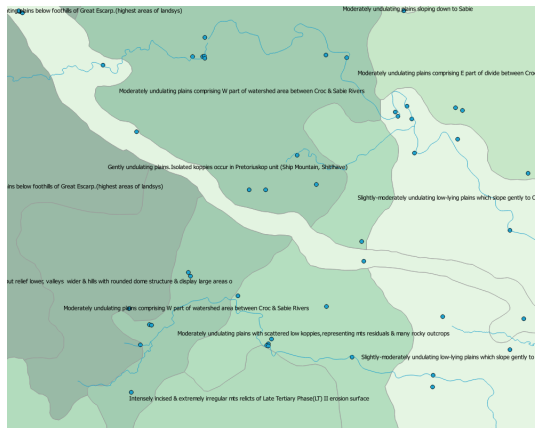

Figure 7: KNP geology map

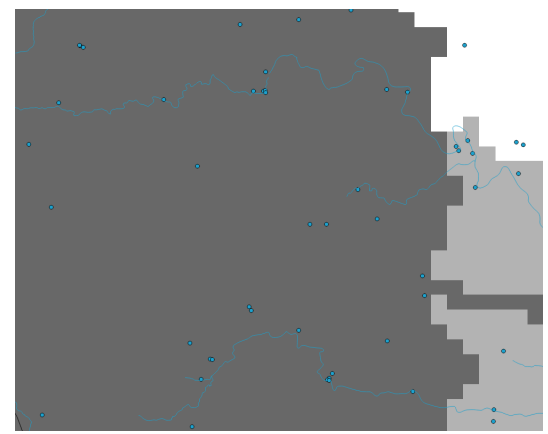

Figure 8: Landscape preference prior map

Typical features that give rise to the heat map in Figure 10 are the distance to water, the vegetation density, the distance to incursion points, the landscape preference (Figure 8), the proximity to static deterrents, and the clustering of historical rhino sightings. The landscape preference (together with the other spatial variables) thus lead to the predicted poaching event heat map as illustrated in Figure 10. Figure 7 and Figure 10 are overlaid to create Figure6. The final step of the validation was to gauge what the experts thought of the heat map and whether it corresponded to both their intuition and to the current poaching situation.

The heat map can be used to involve role players from other areas, such as human trafficking and drugs. They can study the poaching patterns to see if there are similarities between poaching-related events and suspicious or criminal activities in their own areas. In this way we increase the understanding of social issues and start to systematically bring about change in the way the system adapts itself. The heat map and the expert model are thus the primary vehicles for discussion to facilitate this change. 


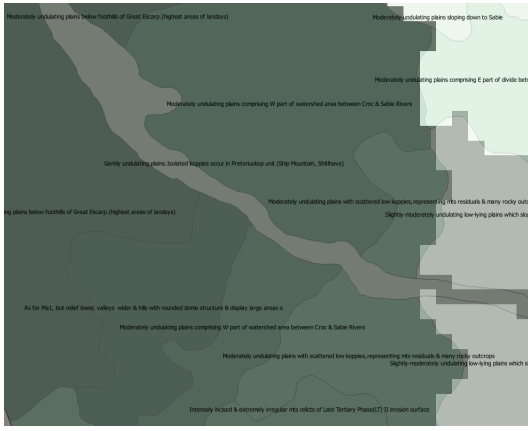

Figure 9: Geology and landscape maps

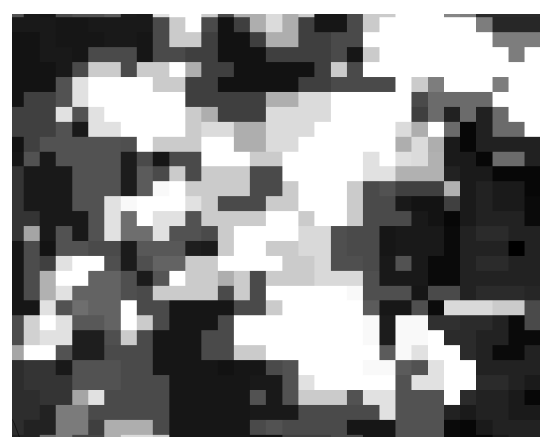

Figure 10: Predicted poaching event heat map

Finally, it was important to consider the statistical validity of the model. The null hypothesis $H_{0}$ tested was that the projections for the heat maps came from the expert driven model. For $\alpha=0.1$, the corresponding value for rejecting $H_{0}$ is $\chi^{2}>29.615$. The calculated $\chi^{2}$ for the final model is 1.93 , which means that heat map projected values could have come from the expert model.

This project started with the need to link probabilities to events, and to be able to determine the probabilities of the states of variables in the network. Over the course of the project this need has shifted more towards the need to understand the problem. The societal and economic factors as well as the inherent reflexive nature of the system have shifted the project in the direction of focussing on understanding the problem of rhino poaching, and not so much on the prediction of future events. If a common understanding exists, we are able to make better decisions and to formulate more effective policies. As Roodt \& Koen (2014) puts it, "The ultimate solution becomes a moving target and the requirements evolve with every sub-system solution developed, as the feedback in the temporal system 'outsmarts' the reactive nature of the solutions." The contribution of this paper is that of a reasoning tool for improved understanding and informed decision making regarding the rhino poaching problem. 


\section{Concluding Remarks}

The main lessons learned during the past few years working on this problem are, firstly, that a coherent, widely acceptable and adaptable system level model is required to aid in developing an understanding amongst all those working to mitigate the problem of rhino poaching, or similar resource plundering activities. Secondly, that appropriately designed, bespoke infrastructure is required to resolve a problem like this. Blindly throwing technology such as night vision goggles, drones and nightly patrols at the problem (although these technologies may be part of a broader coordinated approach) will not work as the solution designer does not understand what the primary (and often linked) drivers are for spatiotemporal poaching events. The third lesson is that collaboration is key; no single team can resolve a "wicked problem" on their own. Working on a complex environmental, social, cultural, financial, and logistical problem requires coordinated efforts from a wide variety of backgrounds and types of expertise.

\subsection{Changing the Understanding}

It is clear that it makes sense to consider a range of socio-economic factors, as the rhino poaching is intricately connected with the dark puzzle of poverty and greed. It is much more difficult to imagine the link between rhino poaching and these external influences when rhino poaching is considered in isolation. In the opinion of the authors, the greatest shift in stakeholders' understanding of the rhino poaching problem occurred on this higher level. The lower level is still not completely understood as there are numerous variables, and even more opinions, to consider. As Popa et al. (2015) put it, "at the core of different sustainability challenges lies the problem of managing complex social-ecological systems under conditions of uncertainty and plurality of values and perspectives."

Initially it was thought that the rhinos were the victims of this horrendous crime. Although it is true that they are sacrificed for their horns, it is now accepted that rhinos are the commodities used as currency for other crimes. 
Crimes such as drug smuggling, human trafficking, and terrorism go hand-inhand with rhino poaching (and other wildlife crimes such as illegal fishing) (Gosling et al., 2014), (Duffy \& St John, 2013), (De Coning \& Witbooi, 2015).

The media painted pictures of sophisticated poaching operations with helicopters dropping poachers down from the sky, armed with night-vision goggles and infra-red technology. The reality is that this is rarely, if ever, true. Poachers are the "foot soldiers" and the lowest workforce for the rhino poaching syndicates. They rarely have more than a rifle or panga with them.

The common wisdom was that rhino poachers adhere to certain rules of thumb. It was generally accepted that this behaviour was predictable, causally based on observed variables/rules. For example, it was thought that poachers preferred certain days or weather conditions. Moon phase, especially the full moon, was initially one of the most influential variables in predicting the behaviour of a poacher. A policy change was made to mitigate the flood of poaching events at the full moon and this in turn caused the poachers to change their operations to no longer prefer the full moon.

We now know that rhino poaching adheres to patterns driven by human decision making within a specific context. Poachers are opportunistic and poach whenever they can; rain or shine. If there is a demand for rhino horn, they will find a way to obtain that rhino horn, by any means necessary. Poaching seems to be linked to festive periods as well as to certain times of the month when the rangers are on leave or are more susceptible to bribery. A clear case can now be made for modelling to include adaptive agents that operate in a world that we now understand better than when the study kicked off. From experience we can see what happens in the environment and what contributes to the problem. This in itself is a necessary and vital step to understand a problem before using other techniques and tools.

\subsection{The Way Forward}

Little was known or shared about the rhino poaching problem when this project started. The only people who had insight into the rhino poaching prob- 
lem were the people faced with it every day: the rangers and the wardens. There existed almost no literature and no rhino poaching models to base the study on and the model presented in this paper is the first of its kind although similar threat models have been developed for other applications. Only in 2015 did a handful of published papers emerge that could be used as comparison to this work, namely the papers by Critchlow et al. (2015) and Park et al. (2015). Critchlow et al. (2015) mainly focused on the drivers behind illegal wildlife as well as modelling ranger patrol routes. Park et al. (2015) predicted poaching locations but by making numerous assumptions they have potentially hindered the future development of their work, for example were they to use their methodology and technology within different research environments. Where Park et al. (2015) worked within a limited geographical space, in contrast, the KNP used in this research covers a much larger area.

The model presented in this paper also showed how the problem of natural resource plundering is different to gang criminal activity impacting on societal sub-groups. Though not perfect, it does facilitate discussions and better decision making surrounding rhino poaching and enable individuals and organisations to reason in a structured way about the problem. It sets the scene for future work that takes a much more inclusive aim at resolving the issues around resource plundering.

Given that we can only train a "best guess" model we conclude that we should not be trying to predict a specific event in time and space, but rather to pre-emptively look for patterns of precursors and events. We need to see how our decisions let agents react. If this work is to be continued, an avenue worth pursuing could be to investigate the use of Agent-Based Modelling (ABM) in conjunction with a set of causal models. ABM will allow us to build in the necessary variability and adaptiveness to observe patterns with a higher and a lower likelihood of development. Emergent patterns can then be studied in the laboratory to "jump" ahead of the system to strike at hot spots before plans of the poachers can come to fruition.

Future work is under way in the form of a project, of which this study 
forms the crucial baseline. This study led to a significant improvement in the study field of rhino poaching as researchers now have the capability (co-created models) to address the problem in a structured transdisciplinary manner. This in itself is a valuable contribution to the knowledge base and to other researchers and beneficiaries.

This study was executed for a large geographical area under a rich infusion of disciplines and experience; it should be possible to scale the approach to a range of similar resource plundering problems in other parts of the world. The model building approach is transferable and deliverers knowledge artefacts (the query-able models) that can be used for longer range strategic planning and for

broad operational purposes. As was mentioned, ABM techniques will enhance these aspects.

\section{References}

Ackoff, R. L. (1971). Towards a system of systems concepts. Management science, 17, 661-671. doi $10.1287 / \mathrm{mnsc} .17 .11 .661$.

Allen, P. (2000). Knowledge, Ignorance and Learning. Emergence, 2, 78-103.

Australian Public Service Commission (2007). Tackling Wicked Problems: A Public Policy Perspective. doi $10.4324 / 9781849776530$.

Boardman, J., \& Sauser, B. (2006). System of systems-the meaning of of. In System of Systems Engineering, 2006 IEEE/SMC International Conference on (pp. 1-6). IEEE. doi 10.1109/SYSOSE. 2006.1652284.

Brown, V., Harris, J., \& Russell, J. (2010). Collective Inquiry and Its Wicked Problems. In Tackling Wicked Problems Through the Transdisciplinary Imagination (pp. 61-81). London: Routledge. (1st ed.).

Craglia, M., Haining, R., \& Wiles, P. (2000). A Comparative Evaluation of Approaches to Urban Crime Pattern Analysis. Urban Studies, 37, 711-729. doi:10.1080/00420980050003982. 
Critchlow, R., Plumptre, A. J., Driciru, M., Rwetsiba, A., Stokes, E. J., Tumwesigye, C., Wanyama, F., \& Beale, C. M. (2015). Spatiotemporal trends of illegal activities from ranger-collected data in a Ugandan national park. Conservation Biology, 29, 1458-1470. doi:10.1111/cobi.12538.

De Coning, E., \& Witbooi, E. (2015). Towards a new 'fisheries crime' paradigm: Challenges and opportunities with reference to South Africa as an illustrative African example. Marine Policy, 60, 208-215. doi 10.1016/j.marpol.2015. 01.006 .

Duffy, R., \& St John, F. (2013). Poverty, poaching and trafficking: what are the links?. Technical Report June. doi/http://dx.doi.org/10.12774/eod\{\_ \}hd059.jun2013.duffy.

Emslie, R. H., \& Brooks, M. (1999). African Rhino: Status Survey and Conservation Action Plan. URL: https://portals.iucn.org/library/efiles/ edocs/1999-049.pdf.

Esbjörn-Hargens, S., \& Zimmerman, M. (2009). Integral Ecology: Uniting Multiple Perspectives on the Natural World. Integral Books.

Finlay, L. (2008). The Reflexive Journey: Mapping Multiple Routes. In Reflexivity: a practical guide for researchers in health and social sciences (pp. 3-20). Blackwell Science Ltd.

Forrester, J. W. (1994). System dynamics, systems thinking, and soft OR. System Dynamics Review, 10, 245-256. doi 10.1002/sdr.4260100211.

Forsberg, K., \& Mooz, H. (1991). The relationship of system engineering to the project cycle. In Proceedings of the International Council for Systems Engineering First Annual Conference (pp. 57-61). doi 10.1080/10429247. 1992.11414684

Gosling, J., Reitano, T., \& Shaw, M. (2014). The Global Response to Transnational Organized Environmental Crime. Technical Report June. 
Gosling, M. (2012). Poison the 'rhino horn'. URL: http://www.iol.co.za/ capetimes/poison-the-rhino-horn-1433583.

Hadorn, G. H., Hoffmann-Riem, H., Biber-Klemm, S., Grossenbacher-Mansuy, W., Joye, D., Pohl, C., Wiesmann, U., \& Zemp, E. (Eds.) (2007). Handbook of Transdisciplinary Research. Springer Science \& Business Media.

Halpern, J. Y., \& Pearl, J. (2001). Causes and Explanations : A StructuralModel Approach Part II: Explanations. In Proceedings of the Seventeenth International Joint Conference on Artificial Intelligence (IJCAI) (pp. 194202).

Inayatullah, S. (2013). The futures of policing: Going beyond the thin blue line. Futures, 49, 1-898. URL: http://linkinghub.elsevier.com/retrieve/ pii/S0016328713000153 doi 10.1016/j.futures.2013.01.007.

Jackson, M. C., \& Keys, P. (1984). Towards a system of systems methodologies. Journal of the operational research society, (pp. 473-486).

Knepell, P. L., \& Arangno, D. C. (1994). Simulation Validation: A Confidence Assessment Methodology. Los Alamitos, CA, USA: IEEE Computer Society Press.

Koen, H., De Villiers, J. P., Pavlin, G., De Waal, A., De Oude, P., \& Mignet, F. (2014). A Framework for Inferring Predictive Distributions of Rhino Poaching events Through Causal Modelling. In 17th International Conference on Information Fusion (FUSION) (pp. 1-7). IEEE Explore.

Korb, K. B., \& Nicholson, A. E. (2010). Bayesian Artificial Intelligence, Second Edition. (2nd ed.). Florida, USA: CRC Press, Inc. doi 10.1198/tech.2005. s836.

Modise, A. (2016). Minister Edna Molewa Highlights Progress in the Fight Against Rhino Poaching. URL: https://www.environment.gov.za/ mediarelease/molewa_highlightsprogress_againstrhinopoaching. 
Mohler, G. O., Short, M. B., Brantingham, P. J., Schoenberg, F. P., \& Tita, G. E. (2011). Self-Exciting Point Process Modeling of Crime. Journal of the American Statistical Association, 106, 100-108. doi:10.1198/jasa.2011. ap09546.

Morin, E. (2007). Restricted complexity, general complexity. In C. Gershenson, D. Aerts, \& B. Edmonds (Eds.), Worldviews, Science and Us: Philosophy and Complexity (pp. 5-29). Singapore: World Scientific.

Morin, E. (2008). On Complexity (Advances in Systems Theory, Complexity, and the Human Sciences). Hampton Press.

Mouton, S. (2012). SANParks Takes Fight to Poachers. URL: http://www.timeslive.co.za/thetimes/2012/12/13/ sanparks-takes-fight-to-poachers.

Muntifering, J. R., Linklater, W. L., Clark, S. G., !Uri- $\neq$ Khob, S., Kasaona, J. K., /Uiseb, K., Du Preez, P., Kasaona, K., Beytell, P., Ketji, J., Hambo, B., Brown, M. A., Thouless, C., Jacobs, S., \& Knight, A. T. (2015). Harnessing values to save the rhinoceros: insights from Namibia. Oryx, (pp. 1-8). doi:10. $1017 /$ S0030605315000769.

Park, N., Serra, E., Snitch, T., \& Subrahmanian, V. S. (2015). APE: A DataDriven, Behavioral Model Based Anti-Poaching Engine. IEEE Transactions on Computational Social Systems, 2, 15-37. doi/http://dx.doi.org/10. 1109/TCSS.2016.2517452.

Popa, F., Guillermin, M., \& Dedeurwaerdere, T. (2015). A pragmatist approach to transdisciplinarity in sustainability research: From complex systems theory to reflexive science. Futures, 65, 45-56. URL: http://dx.doi.org/10.1016/ j.futures.2014.02.002 doi:10.1016/j.futures.2014.02.002.

Rittel, H. W., \& Webber, M. M. (1973). Dilemmas in a General Theory of Planning. Policy Sciences, 4, 155-169. doi 10.1007/BF01405730. 
Roodt, H. (2015). The Recursively Generative Nature of Complex Agri-EcoSocio-Technical Systems: A Transdisciplinary Approach to Developing a Low Carbon Footprint Farming System. In 9th Annual IEEE International Systems Conference (SysCon) (pp. 521-526). Vancouver, BC.

Roodt, H., \& Koen, H. (2014). Engineering Design of an Environmental Management System: A Transdisciplinary Response to the Rhino Poaching Problem. In INCOSE EMEA Sector Systems Engineering Conference. Somerset West.

Sargent, R. (2005). Verification and validation of simulation models. In D. Medeiros, E. Watson, J. Carson, \& M. Manivannan (Eds.), Proceedings of the 1998 Winter Simulation Conference (pp. 121-130).

Schaffernicht, M. (2007). Causality and diagrams for system dynamics. Proceedings of the 2007 International Conference of the System Dynamics Society, (pp. 1-24).

Short, M. B., Mohler, G. O., Brantingham, P. J., \& Tita, G. E. (2014). Gang Rivalry Dynamics Via Coupled Point Process Networks. Discrete and Continuous Dynamical Systems - Series B, 19, 1459-1477. doi 10.3934/dcdsb. 2014.19.1459.

Wang, D., Ding, W., Lo, H., Morabito, M., Chen, P., Salazar, J., \& Stepinski, T. (2013). Understanding the spatial distribution of crime based on its related variables using geospatial discriminative patterns. Computers, Environment and Urban Systems, 39, 93-106. doi:10.1016/j.compenvurbsys.2013.01. 008 .

Woermann, M., \& Cilliers, P. (2012). The ethics of complexity and the complexity of ethics. South African Journal of Philosophy, 31, 447-463. doi:10.1080/02580136.2012.10751787 


\section{List of Figures}

$1 \quad$ A recursive process that accounts for diversity of disciplines to contribute to problem resolution. . . . . . . . . . . . . 7

$2 \quad$ Initial perspective expert knowledge Bayesian Network . . . . . . 11

3 Current iteration of the expert knowledge model . . . . . . . . 15

$4 \quad$ The four quadrants of the mental model (redrawn from EsbjörnHargens \& Zimmerman $[(2009))] \ldots \ldots \ldots$

5 Developing a co-created understanding and model . . . . . . . 20

$6 \quad$ Geology map and predicted heat map overlaid . . . . . . . . . . . 21

$7 \quad$ KNP geology map . . . . . . . . . . . . . . . . . . . 22

$8 \quad$ Landscape preference prior map . . . . . . . . . . . . . . . . 22

$9 \quad$ Geology and landscape maps . . . . . . . . . . . . . . . . 23

10 Predicted poaching event heat map . . . . . . . . . . . . . 23

\section{List of Tables}

$1 \quad$ UL quadrant questions and answers $\ldots \ldots \ldots \ldots$ 